\title{
MEMBANGUN KEPUASAN DAN LOYALITAS PASIEN DARI ASPEK KUALITAS PELAYANAN, CITRA DI RUMAH SAKIT UMUM PKU MUHAMMADIYAH SURAKARTA
}

\author{
BRM. Suryo Triono \\ Staf Pengajar \\ Sekolah Tinggi Ilmu Ekonomi Adi Unggul Bhirawa Surakarta \\ Adi Penawan \\ Staf Pengajar \\ Sekolah Tinggi Ilmu Ekonomi Adi Unggul Bhirawa Surakarta \\ Aris Tri Haryanto \\ Staf Pengajar \\ Sekolah Tinggi Ilmu Ekonomi Adi Unggul Bhirawa Surakarta \\ e-mail : arisharyanto26@yahoo.co.id
}

\begin{abstract}
The purpose of this study is to examine and analyze the significance of the influence of service quality, image on patient satisfaction PKU Muhammadiyah Hospital Surakarta. Test and analyze the significance of the effect of service quality, image, satisfaction on patient loyalty of PKU Muhammadiyah Hospital Surakarta. The population in this study were outpatients in PKU Muhammadiyah Hospital Surakarta with a total of 100 outpatient respondents. The sample in this study were patients at PKU Muhammadiyah Hospital Surakarta with a total of 100 respondents. The results showed that service quality had a positive and not significant effect on patient satisfaction. Citra positive and significant effect on patient satisfaction. Service Quality has a positive and significant impact on patient loyalty. The image of the hospital has a negative and significant effect on patient loyalty. Patient satisfaction has a positive and significant effect on patient loyalty. The path analysis results show the direct effect of service quality on patient loyalty is greater than the indirect effect, so as to increase patient loyalty more effectively through the direct path, the direct effect of hospital image on patient loyalty is smaller than the indirect effect, so as to increase patient loyalty more effective through indirect channels.
\end{abstract}

\begin{abstract}
ABSTRAK
Tujuan penelitian adalah Menguji dan menganalisis signifikansi pengaruh kualitas pelayanan, Citra terhadap kepuasan pasien RSU PKU Muhammadiyah Surakarta. Menguji dan menganalisis signifikansi pengaruh kualitas pelayanan, Citra, kepuasan terhadap loyalitas pasien RSU PKU Muhammadiyah Surakarta. Populasi dalam penelitian ini adalah pasien rawat jalan di RSU PKU Muhammadiyah Surakarta sejumlah 100 responden pasien rawat jalan. Sampel dalam penelitian ini adalah pasien di RSU PKU Muhammadiyah Surakarta sejumlah 100 responden. Hasil penelitian menunjukkan bahwa Kualitas pelayanan berpengaruh positif dan tidak signifikan terhadap kepuasan pasien. Citra berpengaruh positif dan signifikan terhadap kepuasan pasien. Kualitas Pelayanan berpengaruh positif dan signifikan terhadap loyalitas pasien. Citra rumah sakit berpengaruh negatif dan signifikan terhadap loyalitas pasien. Kepuasan pasien berpengaruh positif dan signifikan terhadap loyalitas pasien. Hasil analisis jalur menuinjukkan Pengaruh langsung kualitas pelayanan
\end{abstract}




\section{Buletin Ekonomi}

terhadap loyalitas pasien lebih besar dibandingkan pengaruh tidak langsung, sehingga untuk meningkatkan loyalitas pasien lebih efektif melalui jalur langsung, Pengaruh langsung citra rumah sakit terhadap loyalitas pasien lebih kecil dibandingkan pengaruh tidak langsung, sehingga untuk meningkatkan loyalitas pasien lebih efektif melalui jalur tidak langsung.

Kata Kunci : kualitas, citra, kepuasan pasien, loyalitas pasien

\section{PENDAHULUAN}

Salah satu harapan pasien selaku konsumen, adalah memperoleh pelayanan yang adil dan merata. Bentuk pelayanan yang adil dan merata, hanya dimungkinkan oleh kesiapan psikologis RSU PKU Muhammadiyah Surakarta yang senantiasa menyesuaikan diri dengan perubahan sosial (Social change) dan dinamika pasien sebagai sasaran pelayanannya. Tugas pokok RSU PKU Muhammadiyah Surakarta pada hakekatnya adalah memberikan pelayanan kepada pasien dalam rangka meningkatkan kesejahteraan pasien, sehingga pasien puas dan loyal terhadap RSU PKU Muhammadiyah Surakarta.

Menurut Kotler (2015: 18), bahwa customer loyalty adalah suatu pembelian ulang yang dilakukan oleh seorang pelanggan karena komitmen pada suatu merek atau citra perusahaan. Ada beberapa faktor yang mempengaruhi konsumen atau pelanggan untuk loyal, antara lain faktor kemudahan pelayanan. Menurut Oliver (2010:45), loyalitas pelanggan merupakan suatu komitmen yang dipegang secara kuat untuk membeli kembali atau menggunakan produk atau layanan yang disukai dimasa mendatang meskipun ada pengaruh situasional dan upaya-upaya pemasaran yang memiliki potensi dapat mengubah perilaku.

Parasuraman (2011:165) menyatakan bahwa konsep kualitas layanan adalah suatu pengertian yang kompleks tentang mutu, tentang memuaskan atau tidak memuaskan. Konsep kualitas layanan dikatakan bermutu apabila pelayanan yang diharapkan lebih kecil daripada pelayanan yang dirasakan (bermutu). Konsep kualitas layanan dikatakan memenuhi harapan, apabila pelayanan yang diharapkan sama dengan yang dirasakan (memuaskan). Adapun persepsi tidak memenuhi harapan apabila pelayanan yang diharapkan lebih besar daripada pelayanan yang dirasakan (tidak bermutu).

Menurut Gaspersz (2008:4) pengertian dasar dari kualitas menunjukkan bahwa kata kualitas memiliki banyak definisi yang berbeda dan bervariasi dari yang konvensional sampai yang lebih strategik. Definisi konvensional dari kualitas biasanya menggambarkan karakteristik langsung dari suatu jasa seperti performansi (performance), keandalan (reliability), mudah dalam penggunaan (ease of use), estetika (esthetics) dan sebagainya, seperti kualitas interaksi, kualitas lingkungan fisik dan kualitas hasil.

Menurut Tjiptono (2009:65), citra merupakan bagian dari konsep instansi (Corporate Image) dimana Corporate Image merupakan bagian dari konsep kualitas total jasa. Margaretha (2014:78) menganggap citra sebagai salah satu faktor terpenting dari karakteristik instansi yang dapat membentuk kepercayaan pelanggan terhadap merk atau dalam hal ini proses pelayanan yang diberikan, yang menjadi pandangan masyarakat luas.

Hasil penelitian yang dilakukan Budiarto (2016) menunjukkan bahwa kualitas pelayanan berpengaruh signifikan terhadap kepuasan. Hasil penelitian yang dilakukan Krismanto (2015) menunjukkan bahwa citra berpengaruh signifikan terhadap kepuasan. Hasil penelitian yang dilakukan oleh Budiarto (2016) menunjukkan bahwa kualitas pelayanan dan citra berpengaruh signifikan terhadap loyalitas.

RSU PKU Muhammadiyah Surakarta sebagai organisasi pelaksana pelayanan di wilayah kerjanya harus meningkatkan kualitas pelayanan kepada pasien, karena pada hakikatnya kualitas akan ditentukan atau dinilai oleh pasien. Salah satu cara untuk meningkatkan kualitas pelayanan adalah dengan memenuhi harapan pasien dengan cara 


\section{Buletin Ekonomi}

meningkatkan mutu pelayanan. Rasa puas orang yang memerlukan kualitas pelayanan bisa diartikan dengan membandingkan bagaimana pandangan antara pelayanan yang diterima dengan harapan pelayanan yang diharapkan. Sementara itu harapan pasien dapat terbentuk berdasarkan pengalaman maupun informasi.

Keluaran yang diharapkan RSU PKU Muhammadiyah Surakarta dengan mengedepankan kualitas layanan dan citra rumah sakit adalah kepuasan pasien. Kepuasan pasien merupakan sebuah penilaian dari pasien bahwa mereka menyukai atas jasa atau pelayanan yang diberikan oleh RSU PKU Muhammadiyah Surakarta. Jika kembali pada pemahaman akan konsep pemasaran, maka jelas sekali yang menjadi tujuan setiap aktivitas pemasaran pada RSU PKU Muhammadiyah Surakarta adalah kepuasan pasien. Apabila pasien merasa puas dengan kualitas pelayanan yang diberikan oleh RSU PKU Muhammadiyah Wilayah Surakarta, berarti pihak RSUD mendapat pengakuan atas kinerja (kualitas layanan) dan hal-hal pendukung lain. Hal ini sebagaimana pernyataan Hackman, et.,al, (2016:107) bahwa kepuasan pelanggan memberikan arti adanya pengakuan atas kualitas kinerja dari perusahaan.

Fenomena yang terjadi di RSU PKU Muhammadiyah Surakarta dengan semakin menjamurnya persaingan bisnis di bidang jasa medis yaitu dengan banyak berdirinya klinikklinik kesehatan di wilayah Wilayah Surakarta hal ini dapat dilihat dari pendapatan yang diperoleh atau rasio perlu dioptimalkan kembali agar rasio pendapatan minimal mencapai $30 \%$. Adanya pendirian beberapa rumah sakit baru membuat RSU PKU Muhammadiyah Surakarta harus mampu bersaing secara kompetitif dengan rumah sakit lain. Langkah yang harus dilakukan adalah memberikan pelayanan yang prima yaitu pelayanan excellent service, melayani dengan hati nurani sesuai dengan janji layanan RSU PKU Muhammadiyah Surakarta yang tentunya didukung sarana prasarana atau fasilitas yang ada. Berangkat dari fenomena dan hasil penelitian sebelumnya, maka akan dilakukan penelitian berkenaan dengan pengaruh kualitas pelayanan dan citra terhadap kepuasan dan loyalitas pasien. Adapun judul yang dirumuskan dalam penelitian ini adalah "Membangun Kepuasan dan Loyalitas Pasien dari Aspek Kualitas Pelayanan, Citra di RSU PKU Muhammadiyah Surakarta".

\section{METODE}

Populasi dalam penelitian ini adalah pasien rawat jalan di RSU PKU Muhammadiyah Surakarta sejumlah 100 responden pasien rawat jalan. Menurut Wibisono dalam Riduwan dan Akdon (2013), sampel dalam penelitian ini adalah pasien di RSU PKU Muhammadiyah Surakarta sejumlah 100 responden. Teknik pengambilan sampel menggunakan teknik random sampling, yaitu pengambilan sampel secara acak, sehingga peluang populasi untuk dijadikan sampel sama besar.

\section{ANALISIS DAN PEMBAHASAN}

\section{Hasil Analisis Jalur Persamaan 1}

$\mathrm{Y}_{1}=0,167 \mathrm{X}_{1}+0,325 \mathrm{X}_{2}+\epsilon$

Dengan penjelasan sebagai berikut:

1) Nilai $\beta_{1}=$ koefisien regresi kualitas pelayanan sebesar 0,167 hal ini menunjukan bahwa kualitas pelayanan berpengaruh positif terhadap kepuasan Pasien RSU PKU Muhammadiyah Surakarta. Apabila kualitas pelayanan ditingkatkan, maka kepuasan Pasien RSU PKU Muhammadiyah Surakarta akan meningkat tetapi tidak signifikan.

2) Nilai $\beta_{2}=$ koefisien regresi citra rumah sakit sebesar 0,325 hal ini menunjukan bahwa citra rumah sakit berpengaruh positif terhadap kepuasan Pasien RSU PKU 


\section{Buletin Ekonomi}

Muhammadiyah Surakarta. Hal ini berarti apabila citra rumah sakit baik, maka kepuasan

Pasien RSU PKU Muhammadiyah Surakarta akan meningkat secara signifikan.

Hasil Analisis Jalur Persamaan 2

$\mathrm{Y}_{2}=0,455 \mathrm{X}_{1}-0,166 \mathrm{X}_{2}+0,390 \mathrm{X}_{3}+\epsilon$

Dengan penjelasan sebagai berikut:

1) Nilai $\beta_{1}=$ koefisien regresi kualitas pelayanan sebesar 0,455 hal ini menunjukan bahwa kualitas pelayanan berpengaruh positif terhadap loyalitas Pasien RSU PKU Muhammadiyah Surakarta. Apabila kualitas pelayanan ditingkatkan, maka loyalitas Pasien RSU PKU Muhammadiyah Surakarta akan meningkat secara signifikan.

2) Nilai $\beta_{2}=$ koefisien regresi citra rumah sakit sebesar $-0,166$ hal ini menunjukan bahwa citra rumah sakit berpengaruh negatif terhadap loyalitas Pasien RSU PKU Muhammadiyah Surakarta. Hal ini berarti apabila citra rumah sakit baik atau ditingkatkan, maka loyalitas Pasien RSU PKU Muhammadiyah Surakarta akan menurun namun tidak signifikan.

3) Nilai $\beta_{3}=$ koefisien regresi kepuasan sebesar 0,390 hal ini menunjukan bahwa kepuasan berpengaruh positif terhadap loyalitas Pasien RSU PKU Muhammadiyah Surakarta. Hal ini berarti apabila kepuasan ditingkatkan, maka loyalitas Pasien RSU PKU Muhammadiyah Surakarta akan meningkat secara signifikan.

\section{Uji t}

a. Kualitas pelayanan berpengaruh positif tidak signifikan terhadap kepuasan Pasien RSU PKU Muhammadiyah Surakarta. Hal ini dapat dilihat dari nilai signifikansi yaitu 0,124 > 0,05 . Hasil ini menunjukkan bahwa hipotesis 1 yaitu kualitas pelayanan berpengaruh signifikan terhadap kepuasan pasien RSU PKU Muhammadiyah Surakarta tidak terbukti.

b. Citra rumah sakit berpengaruh positif signifikan terhadap kepuasan pasien RSU PKU Muhammadiyah Surakarta, hal ini dapat dilihat dari nilai signifikansi yaitu 0,003 $<0,05$. Hasil ini membuktikan hipotesis 2 yaitu citra rumah sakit berpengaruh signifikan terhadap kepuasan pasien RSU PKU Muhammadiyah Surakarta atau hipotesis 2 terbukti.

c. Kualitas Pelayanan berpengaruh positif signifikan terhadap loyalitas pasien RSU PKU Muhammadiyah Surakarta, hal ini dapat dilihat dari nilai signifikansi yaitu 0,000 $<0,05$. Hasil ini membuktikan hipotesis 3 yaitu kualitas pelayanan berpengaruh signifikan terhadap loyalitas pasien RSU PKU Muhammadiyah Surakarta atau hipotesis 3 terbukti

d. Citra rumah sakit berpengaruh negatif tidak signifikan terhadap Loyalitas Pasien RSU PKU Muhammadiyah Surakarta, hal ini dapat dilihat dari nilai signifikansi yaitu 0,100 > 0,05 . Hasil ini menunjukkan bahwa hipotesis 4 yaitu citra rumah sakit berpengaruh signifikan terhadap loyalitas pasien RSU PKU Muhammadiyah Surakarta tidak terbukti.

e. Kepuasan pasien berpengaruh positif signifikan terhadap loyalitas pasien RSU PKU Muhammadiyah Surakarta, hal ini dapat dilihat dari nilai signifikansi yaitu 0,000<0,05. Hasil ini membuktikan hipotesis 5 yaitu kepuasan pasien berpengaruh signifikan terhadap loyalitas pasien RSU PKU Muhammadiyah Surakarta atau hipotesis 5 terbukti.

\section{Uji F}

Hasil uji secara serempak (Uji F) pada persamaan kedua diketahui besarnya nilai $\mathrm{F}=$ 19,141 dengan tingkat signifikansi $0,000<0,05$. Sehingga dapat disimpulkan secara bersama-sama variabel bebas yaitu kualitas pelayanan, citra dan kepuasan berpengaruh signifikan terhadap loyalitas pasien.

\section{Koefisien Determinasi atau Varian Total}

Nilai $\mathrm{R}^{2}$ total sebesar 0,495 dapat diartikan loyalitas pasien RSU PKU Muhammadiyah Surakarta dijelaskan oleh variabel kualitas pelayanan, citra rumah sakit dan kepuasan Pasien sebesar $49,5 \%$ dan sisanya 50,5\% dijelaskan variabel lain diluar model penelitian misalnya lokasi, penangan komplain dan prosedur pelayanan. 


\section{Buletin Ekonomi}

Hubungan antar variabel dapat digambarkan dengan bagan sebagai berikut:

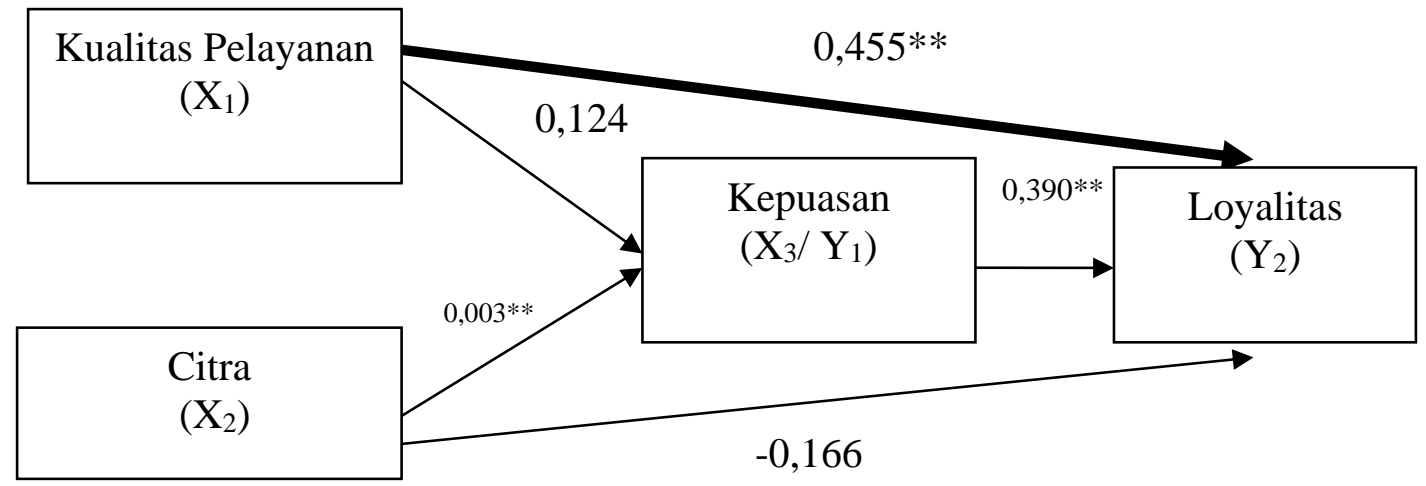

Gambar 1 Pengaruh Langsung Dan Tidak Langsung

\section{Pengaruh Kualitas Pelayanan Terhadap Loyalitas Pasien}

Pengaruh langsung kualitas pelayanan terhadap loyalitas pasien lebih besar dibandingkan pengaruh tidak langsung, sehingga untuk meningkatkan loyalitas pasien lebih efektif melalui jalur langsung. Hal ini mengidentifikasikan bahwa pasien pada RSU PKU Muhammadiyah Surakarta membutuhkan kualitas pelayanan yang baik dan harus memperhatikan faktor-faktor yang dapat meningkatkan kualitas pelayanan sehingga pasien akan tetap loyal terhadap RSU PKU Muhammadiyah Surakarta.

Upaya yang dapat dilakukan seperti memperhatikan faktor-faktor yang dapat meningkatkan kualitas pelayanan antara lain:

a. Adanya petugas parkir di RSU PKU Muhammadiyah Surakarta yang memberikan rasa aman dan nyaman kepada pasien.

b. Pegawai RSU PKU Muhammadiyah Surakarta senantiasa meningkatkan daya tanggap yang baik dalam melayani semua pasien.

c. Sebaiknya RSU PKU Muhammadiyah Surakarta menyediakan area parkir yang lebih memadai.

d. Kualifikasi pegawai RSU PKU Muhammadiyah Surakarta ditingkatkan sesuai dengan tanggung jawab profesi.

e. Pegawai RSU PKU Muhammadiyah Surakarta senantiasa memberikan perhatian yang sama terhadap semua pasien.

\section{Pengaruh Citra rumah sakit Terhadap Loyalitas Pasien}

Pengaruh langsung citra rumah sakit terhadap loyalitas pasien lebih kecil dibandingkan pengaruh tidak langsung, sehingga untuk meningkatkan loyalitas pasien lebih efektif melalui jalur tidak langsung. Hal ini mengidentifikasikan bahwa pasien pada RSU PKU Muhammadiyah Surakarta membutuhkan citra rumah sakit yang baik agar dapat meningkatkan kepuasan pasien yang nantinya akan berimplikasi pada peningkatan loyalitas pasien RSU PKU Muhammadiyah Surakarta.

Upaya yang dapat dilakukan seperti memperhatikan faktor-faktor yang dapat meningkatkan citra rumah sakit agar dapat meningkatkan kepuasan pasien antara lain:

a. Membangun citra RSU PKU Muhammadiyah Surakarta agar menimbulkan kepercayaan pada masyarakat untuk selalu menjaga kesehatan.

b. Senantiasa meningkatkan pelayanan RSU PKU Muhammadiyah Surakarta yang lebih baik dari pada rumah sakit lain.

c. Mempertahankan dan meningkatkan citra RSU PKU Muhammadiyah Surakarta. 


\section{Buletin Ekonomi}

d. Mendorong pelayanan yang lebih baik lagi guna meningkatkan pelayanan kesehatan di RSU PKU Muhammadiyah Surakarta.

e. Meningkatkan unsur kompetensi perusahaan yaitu dengan mengembangkan core business yang dimiliki RSU PKU Muhammadiyah Surakarta.

Upaya yang dapat dilakukan untuk meningkatkan kepuasan adalah dengan melihat indikator-indikator yang dapat meningkatkan kepuasan pasien antara lain:

a. Meningkatkan kepuasan pasien RSU PKU Muhammadiyah Surakarta yaitu dengan menyediakan peralatan kesehatan yang lebih lengkap lagi.

b. Meningkatkan pelayanan yang lebih baik lagi kepada pasien RSU PKU Muhammadiyah Surakarta.

c. Senantiasa memberikan daya tanggap yang baik kepada semua pasien tanpa membedakan pasien satu dengan yang lainnya.

d. Mendorong pegawai RSU PKU Muhammadiyah Surakarta untuk lebih mempunyai rasa empathi dalam memberikan pelayanan yaitu dengan memberikan pelayanan exelent service. lagi.

Kebersihan RSU PKU Muhammadiyah Surakarta selalu diutamakan dan ditingkatkan

\section{KESIMPULAN DAN SARAN}

1. Hasil Uji t dapat disimpulkan bahwa:

a. Kualitas pelayanan berpengaruh positif dan tidak signifikan terhadap kepuasan pasien.

b. Citra berpengaruh positif dan signifikan terhadap kepuasan pasien.

c. Kualitas Pelayanan berpengaruh positif dan signifikan terhadap loyalitas pasien.

d. Citra rumah sakit berpengaruh negatif dan signifikan terhadap loyalitas pasien.

e. Kepuasan pasien berpengaruh positif dan signifikan terhadap loyalitas pasien.

2. Hasil analisis jalur menunjukkan bahwa :

a. Pengaruh Kualitas pelayanan Terhadap Loyalitas pasien

Pengaruh langsung kualitas pelayanan terhadap loyalitas pasien lebih besar dibandingkan pengaruh tidak langsung, sehingga untuk meningkatkan loyalitas pasien lebih efektif melalui jalur langsung.

b. Pengaruh citra rumah sakit Terhadap Loyalitas pasien

Pengaruh langsung citra rumah sakit terhadap loyalitas pasien lebih kecil dibandingkan pengaruh tidak langsung, sehingga untuk meningkatkan loyalitas pasien lebih efektif melalui jalur tidak langsung.

\section{SARAN}

1. Kualitas pelayanan rumah sakit merupakan variabel yang paling dominan mempengaruhi loyalitas pasien RSU PKU Muhammadiyah Surakarta. Untuk itu akan lebih baik apabila RSU PKU Muhammadiyah Surakarta dalam peningkatan loyalitas pasien lebih meningkatkan kualitas pelayanan yang lebih baik lagi upaya yang dapat dilakukan antara lain:

a. Pegawai RSU PKU Muhammadiyah Surakarta senantiasa memiliki daya tanggap yang baik yaitu cepat dan tepat terhadap semua pasien, misalnya ketika pasien datang ditanggapi dengan baik dan dipersilahkan dengan baik dan sopan.

b. Meningkatkan kualifikasi pegawai RSU PKU Muhammadiyah Surakarta sesuai dengan profesi dengan meningkatkan pelatihan-pelatihan, seminar, workshop, studi banding, dll.

c. Sebaiknya RSU PKU Muhammadiyah Surakarta menyediakan fasilitas tempat parkir yang lebih memadai dengan membangun area parkir baru dan penataan parkir yang 


\section{Buletin Ekonomi}

lebih baik lagi dengan didukung adanya petugas parkir yang selalu memberikan rasa aman dan nyaman kepada pengunjung utamanya pasien, misalnya adanya keamanan data pasien yang tidak diberikan kesemua orang.

Supaya menjadi variabel intervening yang lebih efektif, maka dalam hal ini kepuasan pasien lebih diperhatikan atau diutamakan lagi dapat dilihat dari segi pelayanan, sarana prasarana sehingga apa yang diharapkan RSU PKU Muhammadiyah Surakarta yaitu meningkatkan loyalitas pasien dapat tercapai.

\section{DAFTAR PUSTAKA}

Anderson, E. and B. Weitz, 2013. "The Use of Pledges to Build and Sustain Commitment in Distribution Channel", Journal of Marketing research 29 (1), p.18-34.

Budiarto. 2016, "Pengaruh Kualitas Pelayanan terhadap Loyalitas Nasabah dan Reputasi Bank sebagai Variabel Intervening pada Apotek K-24 Jogjakarta” UNS, Surakarta.

Bolton, Ruth N and james H. Drew. 2011, “A Multi Stage Model of Customers Assessment of Service Quality and Value", Journal of Consumer Research, Januari, 1-9.

Bontis, Nick and Lorne D.Booker. 2015. " The mediating effect of organizational reputation on customer loyalty and service recommendation in banking industry", Journal Management Decion, Vol.45, No.9 p.1426-1445.

Cronin J.Joseph Jr and Steven A. Taylor. 2012. " Measuring Service Quality : A reexamination and extension", Journal of Marketing Vol. 56 (July) p.55 - 68

Fornell, Claes; Johnson, Michael D ; Anderson, Eugene W ; Cha, Jaesun; Bryant, Barbara Everitt. 2016. "The American Customer Satisfaction Index : Nature, Purpose, and Findings". Journal of Marketing, 60 (10). (7-18).

Ghozali, Imam. 2012. Aplikasi Analisis Multivariate Dengan Program SPSS . 2010. Analisis Regresi. Jakarta: Salemba Empat.

Gujarati, Damodar. 2010. Ekonometrika Dasar. Erlangga. Jakarta.

Herbig, Paul, John Milewicz and Jim Golden. 2014. "A Model of Reputation Building and Destruction "Journal of Business Research. Vol.31, June 1994, No. 1 ; p.23-31.

Hackman, Poul, Shiill. 2016. Satisfaction Analysis. New York: Mc. Graw-Hill.

Istijanto. 2016, Riset Sumber Daya Manusia, Jakarta:PT. Gramedia Pustaka Utama

Juran, J.M. 2011, Quality Control Handbook, New York: Mc. Graw-Hill.

Kotler, Philip. 2013. Marketting Management, $11^{\text {th }}$ ed. Upper Saddle River, New Jersey : Prentice Hall, Inc. 


\section{Buletin Ekonomi}

L.Berry, Parasuraman, A.,A.Zeithmal, V.,\&L. 2014. ”A conceptual Model of Service Quality and Its Implications for Future Research”, Journal of Marketing, Vol.49 (fall).

Liu, Tsung-Chi and Li Wei Wu. 2015. "Customer retention and cross-buying in the banking industry : An Integration of service attributes, satisfaction and trust" Journal of Financial Service Marketing, Vol.12 No.2 p.132-145.

Mark P, Prichard. 2010. "Analyzing the Commitment-Loyalty Link in Service Contexts", Journal of the Academy of Marketing Science 27 (3), p.333-348

Margaretha M. 2016. "Study Mengenai Loyalitas Nasabah Divisi Asuransi Kumpulan AJB Bumi Putera 1912 (Studi khusus di Jawa Tengah)", Jurnal Sains Pemasaran Indonesia, Vol III, No.3, Desember 2004. (289-308)

Oliver, Richard L. 2014. "Satisfaction : A Behavioral Perspective on the Customer", McGraw-Hill, New York, NY

Pangestu, Djarwanto dan Subagyo. 2011: Statistik Induktif, Edisi: 4, Yogyakarta: BPFE.

Rosinta, Dwi Aryani Dan Febrina. 2015. Pengaruh Kualitas Layanan Terhadap Kepuasan Pelanggan Dalam Membentuk Loyalitas Pelanggan. Jurnal Ilmu Administrasi Dan Organisasi, Mei-Agus 2010, Hlm. 114-126. Volume 17, Nomor 2. ISSN 0854-3844

Riduwan. 2014. Skala pengukuran Variabel-Variabel Penelitian, Cetakan Ketiga, Alfabeta, Bandung.

Selnes, Fred. 2013. "An Examination of the effect of Product Performance on Brand Reputation, Satisfaction and Loyalty", European Journal of Marketing, 27 (9). (19$35)$.

Solomon, Michael. 2016. Consumer Behavion, $3^{\text {th }}$ edition, McGraw Hill.

Sugiyono. 2014. Metodologi Penelitian Bisnis, Cetakan Ketujuh, CV. Alpabeta, Bandung.

Suharsini, Arikunto. 2011. Prosedur Penelitian Suatu Pendekatan Praktek Edisi ketiga.

W., Brown, Stephen, 2011, “A Multi Stage Model of Customers Assesment of Service Quality and Value", Journal of Marketing, April, pp. 92-98

Zeithaml, V. 2012. Consumer Perceptions of Price, "Quality, and Value : Means End Model and Synthesis of Evidence", Journal of Marketing, Vol 52, July, p.2-22

Zeithaml, Valerie; Berry, Leonard L,; and Parasuraman, A. 2014. "Sevqual: Multiple Item Scale for Measuring Consumer Perceptions of Service Quality", Journal of Retailing, Vol 64 No.1 Spring. 